\title{
Decision making problems: AIDS prevention and energy development
}

\author{
G. Dzemyda, V. Šaltenis and V. Tiešis \\ Institute of Mathematics and Informatics \\ Akademijos St., Vilnius 2600, Lithuania. \\ Tel.: +3702 623724; Fax: 729209 \\ e-mail: dzemydaeosts.mii.lt
}

\begin{abstract}
The problems of simulation and control of the HIV/AIDS infection spread and search for the optimal energy development strategy were investigated. The decisions in both applications are of great importance, because they have an influence on the main social and economic conditions of the society.
\end{abstract}

\section{Keywords}

HIV/AIDS infection, simulation, multicriteria decision support, energy development.

\section{INTRODUCTION}

Two problems of decision making are presented in this paper. In both cases optimal decisions were the objective of investigations. The first problem deals with the investigation of the HIV/AIDS infection spread. The goal is to determine the optimal level of preventive means allowing to slow down the infection spread and to plan the activities of health services. The second problem is to search for the optimal energy development strategy. It is necessary to select the best alternative from the finite set. In both applications the human decision is the final. A specialized computer software is developed for each multiple criteria application.

\footnotetext{
${ }^{1}$ The work was partly supported by the Lithuanian State Science and Education Foundation (grants No.141 and No.143, 1995.03.31).
} 


\section{AIDS PREVENTION}

Several models are now available for studying AIDS epidemic spread within specific risk groups and among them (Dzemyda, Šaltenis and Tiešis, 1994; Kaplan 1990). These models characterize the dynamics and intercourse within and among the risk groups of individuals (e.g. homosexual men, highly promiscuous heterosexual men and women, drug users) and allow to analyze the means having the greatest influence on the spread rate. Our model describes any risk group by three differential equations, which simulate the dynamics of the amount of active susceptible $x_{i}$, active infected $y_{i}$, and passive (not spreading the infection) infected individuals $z_{i}$ :

$$
\begin{aligned}
& \frac{d x_{i}}{d t}=u_{i}^{x}-\left(\mu^{i}+\mu_{2}^{i}\right) x_{i}-\frac{x_{i}}{x_{i}+y_{i}} \sum_{j=1}^{n} b_{i j} p_{i j} y_{j} \\
& \frac{d y_{i}}{d t}=u_{i}^{y}+\frac{x_{i}}{x_{i}+y_{i}} \sum_{j=1}^{n} b_{i j} p_{i j} y_{j}-\left(\mu^{i}+\mu_{1}+\mu_{2}^{i}+k_{i}+k_{a}\right) y_{i} \\
& \frac{d z_{i}}{d t}=u_{i}^{z}+\left(k_{i}+\mu_{2}^{i}+k_{a}\right) y_{i}-\left(\mu_{i}+\mu_{1}\right) z_{i}, \quad i=1,2, \ldots, n,
\end{aligned}
$$

where

$n$ is the number of groups;

$u_{i}^{x}, u_{i}^{y}, u_{i}^{z}$ are the numbers of susceptible, active infected and passive infected

individuals, respectively, recruited into the group per time unit; $u_{i}^{x}$ depends on the number of adolescents and on the immigration-emigration balance, $u_{i}^{y}, u_{i}^{z}$ depends on the infection due to foreign relations

$\mu^{i}, \mu_{1}$ are the mortality rates not due to AIDS and due to AIDS, correspondingly; $\mu_{2}^{i}$ is the rate at which an individual naturally becomes inactive (but does not die); $k_{i}$ is the rate at which an infected individual becomes inactive because of blood test for HIV;

$k_{a}$ is the rate of transition from HIV infected to AIDS;

$b_{i j}$ is the averaged number of contacts of an individual from group $j$ with the persons from group $i$ per unit time;

$p_{i j}$ is the probability of infecting a susceptible person from group $i$ by an infected one from group $j$ per contact.

The model (1)-(3) of HIV/AIDS transmission requires to estimate both the initial extent of infection and various rates: mortality, partner-changing, prophylaxis and other ones. Some of these parameters may be evaluated directly from the statistical data. The estimates of transmission probabilities vary in a wide range. For example, the average probability for 
heterosexuals varies from 0.001 (Longini et al., 1988) to 0.0018 (Laga et al., 1988) or even to overestimated upper bound 0.011 (Goedert $e t$ al., 1988), used by Stigum et al. (1991).

The balance of contacts must be satisfied:

$N_{j} \cdot b_{i j}=N_{i} \cdot b_{j i}$, where $N_{j}=x_{j}+y_{j}$.

The individuals from the same group can have various rates of contacts. Let the percentage of individuals $N_{j}^{k}$ has rate $b_{i j}^{k}$. May and Anderson (1987) and Jacquez and

Simon (1990) have considered weighted mean contact rate:

$b_{i j}=\frac{\sum_{k}\left(b_{i j}^{k}\right)^{2} N_{i}^{k}}{\sum_{k} b_{i j}^{k} N_{i}^{k}}$

The main control parameters are such:

- $K^{i}$ is the percentage of persons tested for the AIDS per year;

$-\alpha_{i}$ is the percentage of protected sexual contacts.

These parameters are related with the model (1)-(3) as follows:

$$
\begin{aligned}
& k_{i}=v^{i} K^{i} / 10000, \\
& p_{i j}=p_{i j}^{*}\left(1+\alpha^{j}\left(r_{i j}-1\right) / 100\right),
\end{aligned}
$$

where

$-v^{i}$ is the annual percentage of individuals terminating the infection spread after diagnosing it;

- $p_{i j}^{*}$ is the transmission probability per unprotected contact;

- $r_{i j}$ is the probability of protection failure.

In the beginning of the infection spread the parameters $p_{i j}^{*}, k_{a}$ and $\mu_{1}$ must be treated as increasing with time, because the percentage of individuals with later stages of HIV increases (Longini et al., 1988). Their values are minimal at the beginning of infection spread and increase until some value. Dzemyda, Šaltenis and Tiešis (1993) proposed to use linear increasing function approximating such an increase.

The aim of investigations was to determine the optimal values of two control parameters (the percentage of HIV/AIDS blood tests $K^{i}$ and the percentage of usage of preventive means $\alpha_{i}$ ) when the HIV/AIDS infection may be stopped. Both computational experiments and analytical investigations were performed.

Let us consider a case without an import of the infection, i.e. $u_{i}^{y}=0$. Let $y=\sum_{i=1}^{n} y_{i}$, $\mu_{s}^{i}=\mu^{i}+\mu_{1}^{i}+\mu_{2}^{i}$. Then we have, that $d y / d t \leq 0$ for any $x_{i}$ and $y_{i}$, if and only if 


$$
\sum_{i=1}^{n} b_{i j} p_{i j}^{*}-\mu_{s}^{j}-k_{\alpha} \leq k_{j}+\left(\alpha^{j} / 100\right) \sum_{i=1}^{n} b_{i j} p_{i j}^{*}\left(1-r_{i j}\right), j=\overline{1, n}
$$

That is, the spread of infection decreases in the case (4). In Figure 1 the points mark the area where (4) is satisfied for Lithuanian homosexuals. The values of transmission probabilities were assumed to be equal to 0.01 and 0.002 for single anal and heterosexual contact, respectively. On the left the rather optimistic case is shown assuming that the HIV positive person decreases his personal spread in 10 times $\left(v^{1}=90 \%\right)$ after diagnosis the infection. The case for $v^{\prime}=50 \%$ is shown on the right. The present level of AIDS tests is $K^{1}=6 \%$. Most likely this level will remain the same in the near future. From Figure 1 it follows that the necessary level of protected sexual contacts is $65 \%$ when $v$ lies in the interval $[50,90]$.

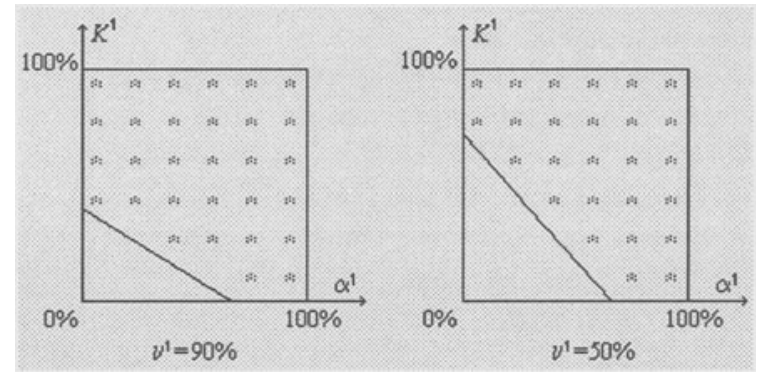

Figure 1 The regions were HIV infection decreases.

The economical and social prices of both control parameters (the percentage of HIV/AIDS blood tests $K^{i}$ and the percentage of usage of preventive means $\alpha_{i}$ ) grow with an increase of their values. Therefore, the boundary (4) dividing the definition area into the regions of increase and stabilization of infection, may be treated as the Pareto set of optimal solutions. The problem is to minimize the total cost of preventive means.

The infection spread in Lithuania was investigated by means of computational experiments for $n=3$ (homo/bisexual men, promiscuous heterosexual men and women). The values of $\alpha_{i}$ and $K^{i}$ were varied. Assumptions were made that the usage of protective means during sexual contacts $\alpha\left(\alpha=\alpha^{i}, i=1,2, \ldots, n\right)$ grows from the initial value $\alpha_{1}=10 \%$ to $\alpha_{2}$ that is the forecasted value of $\alpha$ at the end of the simulation period. If the upper bounds of transmission probabilities are used, then the simulation shows that the infection spread may be stoped when $\alpha_{2}=85 \%$ and $20 \%$ of the every risk group undergo the HIV/AIDS blood tests (Dzemyda, Šaltenis and Tiešis, 1994). In the case of present level of HIV/AIDS tests $\left(K^{i}=6 \%\right.$ ) the level of $\alpha_{2}$ stabilizing the infection spread is equal to $65 \%$ if the medium probabilities are used in the model (the average transmission probability for heterosexuals is equal to 0.002 ). These results correspond with that obtained analysing (4). 


\section{MULTIPLE CRITERIA DECISION SUPPORT IN ENERGY DEVELOPMENT}

The multiple criteria support system (Dzemyda and Šaltenis, 1994) solves the problem of selecting the best alternative (plan, item, option, candidate, and so on) from the finite set. Any alternative is characterized by several criteria. The criteria may be expressed as some values (e.g. capacity, power, weight), but abstract, verbal criteria (e.g. requirement, feasibility, social effect) are possible, too. The system is used to solve the problem with the help of judges (experts, voters). It allows to systematize the judge's knowledge and experience.

Three methods of increasing complexity are realized by the system:

- paired comparisons of alternatives (see Karpak and Zionts (1989)),

- Pareto (see Karpak and Zionts (1989)),

- Fuzzy (see Zhang Li Li and Chang Da Young (1992)).

The method of paired comparisons is the simplest one. The judge must only compare the alternatives, two at a time, and determine which of the two alternatives is better (or equivalent).

The Pareto method offers the Pareto subset of alternatives to the judge. He varies the weights of criteria and looks for the best alternative from this subset.

The Fuzzy method is similar to that of Pareto, only the judge has an opportunity to doubt as to his opinion. Naturally, such an approach requires for much more information from the judge and is most complicated. The reasons for which the Fuzzy approach may be more adequate are:

- uncertainty of a decision maker as to his preferences (hesitation),

- lack of information,

- existence of different opinions (in the group choice).

The procedure of normalizing the criteria values (within the interval 1-10) must be used by the judge prior to the usage of the methods (except the paired comparisons method). It is essential in the case of verbal criteria.

The decision support methods are linked by the common use of data. That provides some integration among these methods. Each part of the system uses the following information from the specialized data base:

- names of alternatives.

- names and values of criteria;

- names of judges;

- intermediate dialog actions of each judge;

- results of each judge;

- integral results.

The flow chart of the system is given in Figure 2. 


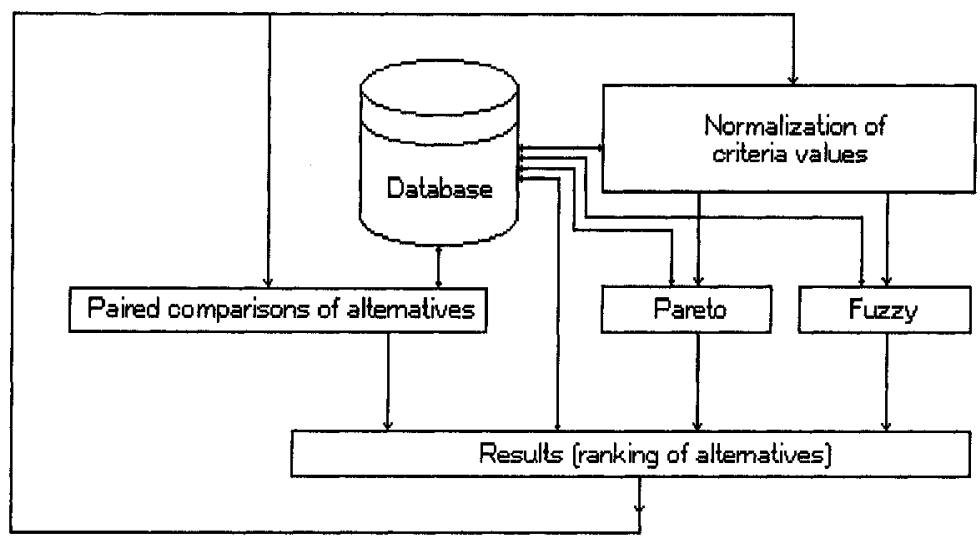

Figure 2 Flow chart of the system.

The main applications of the system were in the scope of decisions on the best energy development strategy for Lithuania. The urgent energy problems are related to the nuclear safety and night power consumption of Ignalina Nuclear Plant (2500 MW). The alternatives covered various scenarios of nuclear plant development, fuel import, electricity export, environmental impact, and so on.

Table 1 of alternatives illustrates the problem of reconstruction of the Kruonis Pumped Storage Hydro Power Plant (Hydro), Ignalina Nuclear Plant (Nuclear) and installation of the night electric heaters (Heaters).

Table 1. The description of alternatives.

\begin{tabular}{|c|c|c|c|}
\hline $\begin{array}{c}\text { Short name of } \\
\text { alternative }\end{array}$ & $\begin{array}{c}\text { Number of } \\
\text { turbines } \\
\text { in Hydro }\end{array}$ & $\begin{array}{c}\text { Number of } \\
\text { reactors in Nuclear }\end{array}$ & $\begin{array}{c}\text { Power of } \\
\text { Heaters (MW) }\end{array}$ \\
\hline H-2, A-2 & 2 & 2 & - \\
H-3, A-2 & 3 & 2 & - \\
H-4, A-2 & 4 & 2 & - \\
H-0, A-1 & - & 1 & - \\
H-2, A-2, 400 & 2 & 2 & 400 \\
H-0, A-2, 800 & - & 2 & 800 \\
\hline
\end{tabular}

Ten criteria (export of energy, fuel saving, degree of nuclear risk, and so on) were used by judges to solve the problem of reconstruction of the Pumped Storage Hydro Power Plant, Ignalina Nuclear Power Plant, and installation of the night electric heaters.

The result was the ranking of alternatives by various methods. It is presented in Table 2 . 
Table 2. The ranking of alternatives: weights and order numbers.

\begin{tabular}{|c|c|c|l|}
\hline \multirow{2}{*}{$\begin{array}{c}\text { Short name } \\
\text { of alternative }\end{array}$} & \multicolumn{3}{|c|}{ Methods } \\
\cline { 2 - 4 } & $\begin{array}{c}\text { Paired } \\
\text { comparis } \\
\text { ons }\end{array}$ & Pareto & Fuzzy \\
\hline H-2, A-2 & $1.00(1)$ & $0.96(2)$ & $0.94(4)$ \\
H-3, A-2 & $0.83(2)$ & $0.96(3)$ & $0.95(3)$ \\
H-4, A-2 & $0.67(4)$ & $0.96(4)$ & $0.95(2)$ \\
H-0, A-1 & $0.50(6)$ & $0.90(5)$ & $0.78(6)$ \\
H-2, A-2, 400 & $0.67(5)$ & $1.00(1)$ & $1.00(1)$ \\
H-0, A-2, 800 & $0.83(3)$ & $0.87(6)$ & $0.79(5)$ \\
\hline
\end{tabular}

The software for decision support is meant for general purposes. It may be successfully used to solve any other applied problem of similar type.

\section{CONCLUSIONS}

The decisions in both applications are of great importance, because they have an influence on the main future social and economic conditions of the society. Therefore the results of the epidemic spread simulation or the evaluation of the energy alternatives are not used directly. They may be treated as well founded advice for decision makers.

The software is available to PC AT of all modifications. It is suitable to the modifications of models and input data during the investigations.

\section{REFERENCES}

Dzemyda, G., Šaltenis V. (1994) Multiple criteria decision support system: methods, user's interface and app'ications. Informatica, 5(:-2), $3:-42$, Vi'nius.

Dzemyda, G., Šaltenis, V. and Tiešis, V. (1993) Control of the HIV/AIDS infection spread. 12th IFAC World Congress, Preprints of Papers, Vol.4, Sydney.

Dzemyda, G., Šaltenis, V. and Tiešis, V. (1994) Means for the HIV/AIDS infection control. Proceedings of the Asian Control Conference, 1, 13-16, Tokyo.

Goedert, J.J., Eyster, M.E., Ragni, M.V., Biggar, R.J. and Gail, M.H. (1988). Rate of heterosexual HIV transmission and associated risk with HIV-antigen. IV-International Conference on AIDS, Abstract 4019, Stockholm.

Jacquez, J.A. and Simon, C.P. (1990) AIDS: The epidemiological significance of two different mean rates of partner change. IMA Journal of Mathematics Applied in Medicine and Biology, 7, 27-32.

Kaplan, E.H. (1990) An overview of AIDS modeling. New Directions for Program Evaluation, 46, 23-36. 
Laga, M., Taelman, H., Bonneux, L., Cornet, P., Vercauteren, G. and Piot, P. (1988) Risk factors for HIV infection in heterosexual partners of HIV infected Africans and Europeans. IV-International Conference on AIDS, Abstract 4004, Stockholm.

Longini, I.M., Clark, W.S., Haber, M. and Horsburgh, R. (1989). The stages of HIV infection waiting times and infection transmission probabilities. In Lecture Notes in Biomathematics, 83, 112-137.

May, R.M. and Anderson, R.M. (1987) Transmission dynamics of HIV infection. Nature, 326, 137-142.

Stigum, H., Gronnesby, J.K., Magnus, P., Sundet, J.M. and Bakketeig L.S (1991). The potential for spread of HIV in the heterosexual population in Norway: a model study. Statistics in Medicine, 10, 1003-1023

Zhang $\mathrm{Li} \mathrm{Li}$ and Cheng De Yong (1992). Extent analysis and synthetic decision. In Support Systems for Decision and Negotiation Processes, Preprints of the IFAC/IFORS/IIASA/TIMS Workshop, Vol. 2. System Research Institute, Warsaw.

Karpak, B. and Zionts, S. (Eds., 1989) Multiple Criteria Decision Making and Risk Analyzis Using Microcomputers. NATO ASI Series, Series F: Computer and System Sciences, Vol. F56. Springer. 